\title{
Preliminary Work on an Early Warning and Rapid Response Program for Moderate Earthquakes
}

\author{
by Craig W. Scrivner and Donald V. Helmberger
}

\begin{abstract}
Warning of imminent ground shaking due to a large earthquake would be useful to a variety of agencies. This kind of ground-motion prediction is possible in southern California for events with magnitude less than 6, where path effects dominate. The 28 June 1991 Sierra Madre earthquake is presented as a test case for this concept. A single-station inversion of the record from the Pasadena station 20 $\mathrm{km} \mathrm{SW}$ of the epicenter produces reasonable source parameters for the event. With these source parameters and a library of Green's functions calculated for an average southern California crustal model, ground motions can be predicted throughout the region. In particular, since the peak displacement for the Sierra Madre event occurs at Pasadena before ground motion begins at a station near the San Andreas Fault in San Bernardino, ground motions near the San Andreas Fault can be calculated before the seismic energy has propagated into the area. Considering this scenario in the reverse direction, records from a station near an earthquake on the San Andreas Fault could be used to predict ground motions in the metropolitan Los Angeles area. Broadband, high-dynamic-range seismic instruments produce high-quality records for events over a wide magnitude range. Thus, the development of a warning system can be approached in stages, starting with small events. With path effects determined by modeling moderate-size events, work can begin on developing distributed fault models to predict ground motions of great earthquakes.
\end{abstract}

\section{Introduction}

The prospects for accurate prediction of earthquakes remain as poor now as they have throughout this century. Other areas of study in seismology, however, have experienced significant advances that can be put to use for seismic hazard abatement in urban areas (NRC, 1991). Routine location of seismic events has been increasingly automated. These efforts have moved from associating network data previously recorded to tape (Crampin and Fyfe, 1974) to processing data as it is received (Stewart, 1977). A number of automated networks have been set up around the world in the last decade (some examples are Michael et al., 1982; Uski, 1990; Bache et al., 1990; Reymond et al., 1991; Horiuchi et al., 1992; Roberts et al., 1993). As networks have gone to digital recording and computer speed has increased, the response time has improved and parameters describing a seismic event are often available within minutes after the event. Picking and locating events using a single three-component station has also been shown to be viable (Magotra et al., 1989), and offers even shorter response times. Data recorded by a station near an event can provide warning of incoming seismic energy to more distant locations (Nakamura, 1988).

Broadband digital instruments record high-quality waveforms for both strong and weak motions. Because these stations can record smaller, more numerous, events as well as large hazardous events, a catalog of Green's functions can be developed for an area and used to find source characteristics for large events. The records of the small events can be used either directly as empirical Green's functions or as a basis for crustal models to calculate synthetic Green's functions. The advantage of theoretically derived Green's functions is that they can be calculated for any range and depth. They can also be stored as the response for three fundamental faults. These responses can be combined to produce the three-component response for an arbitrary point source by a weighted sum determined by the strike, rake, and dip. With the catalog of Green's functions, rapid inversions for a source parameter can be done (Dreger and Helmberger, 1993; Zhao and Helmberger, 1994). These inversion techniques work well for sparse networks of broadband data.

This raises the possibility that data from a single nearfield broadband receiver would be enough to determine source parameters and predict ground motions throughout the region. Using this strategy, we could predict ground motions in areas, like the Los Angeles basin, where seismic energy is focused and heavy damage is possible. How these 
predicted ground motions could be used depends on where the event occurred. If the earthquake occurs within an urban area, the calculated ground motions could be useful for rapid assessment of areas of greatest damage. If the earthquake occurs outside an urban area, the ground motions for the urban zone can be calculated before the energy propagates into the area. In this case, the calculations serve as a prediction of imminent ground motions, and warnings could be posted to organizations for emergency machinery shutdown or other response (NRC, 1991). Many cities have been built in the vicinity of faults capable of producing damaging earthquakes. For this reason, the scheme presented here for early warning and ground-motion prediction could be widely applied. The strategy can be considered an extension of studies done with broadband data recorded at regional distances by a single broadband station or a sparse network of them (Ekström et al., 1986). Rather than wait for a complete network solution, estimates are made with data as data are received. More detailed solutions follow after waveforms are retrieved from slower sources of data.

In this article, we begin testing the credibility of the strategy discussed above. We give an example of using data from a single broadband station to invert for the source parameters of strike, rake, and dip. These parameters are used to calculate ground motions for the locations of other receivers, and the calculations are compared with the data from these sites. The source inversion is repeated with increasing amounts of data to show how the source mechanism found in the inversion improves and stabilizes with additional data. The intent of this exercise is to explore the potential within the data for rapid, single-station source inversion. Many of the practical details of developing and implementing a realtime system are not discussed in this article.

\section{Outline of Proposed Method}

When an earthquake occurs, it must be recognized and located by the closest station. The mechanics of this problem are not discussed in this article. Procedures to pick an event with a single station and determine the backazimuth from the first-motion amplitudes of the three components by rotating the $P$ waves into a tangential node have been developed by Magotra et al. (1987) and Nakamura (1988). Kanamori (personal communication) has computer software in development that estimates the location of an event with data from a single broadband station. We use the location generated by this software as the epicenter in our inversion (Ta-

Table 1

Event Location

\begin{tabular}{lcc}
\hline \multicolumn{1}{c}{ Location Method } & $\begin{array}{c}\text { Latitude } \\
\text { (N) }\end{array}$ & $\begin{array}{c}\text { Longitude } \\
\text { (W) }\end{array}$ \\
\hline USGS/CIT network & 34.261 & 117.996 \\
Single station (PAS) & 34.249 & 118.009 \\
\hline
\end{tabular}

ble 1). The distance from source to receiver is not known until the $S$ wave arrives, but it would be preferable to start the source inversion as early as possible. At a given moment, after the $P$ wave and before the $S$ wave, the time since the $P$ wave constrains a minimum possible distance because we know that a station closer than this distance would already have recorded shear waves. As a result, the inversion can be started with this constraint. The minimum possible range is increased until the $S$ wave arrives and the distance for the single-station inversion can be fixed. With the location of the event determined, the distance and backazimuth from the source to other stations in the network can be calculated. As these stations begin recording the event, the data can be included in the inversion process. The source inversion is repeated with increasing amounts of data. After each inversion, ground-motion predictions are calculated with the source parameters for sites throughout the region.

The inversion technique used in this article does a grid search over the source mechanism parameter space while allowing different segments of the waveform to shift in time independently (Zhao and Helmberger, 1994). The error of the synthetic waveform relative to the data is found for each set of possible source parameters. The grid search is first done with a coarse mesh to roughly determine the global minimum in the error. A search over a finer grid centered on the coarse mesh minimum refines the solution. The general scheme for early warning can be implemented with other inversion techniques. Advantages of the technique of Zhao and Helmberger are that it can work with broadband data, that it can work with arbitrary portions of the data, and that it allows portions of data to shift relative to each other during the inversion. The flexibility with which this technique handles portions of data makes it relatively insensitive to flaws in the crustal model used to calculate Green's functions.

\section{Results for Sierra Madre}

Figure 1 is a map of southern California with the location of the 28 June 1991 Sierra Madre $(M=5.8)$ mainshock and the TERRAscope broadband seismic stations used in this study. The source mechanism shown was found by Dreger and Helmberger (1991) with the complete waveforms from these stations and refined Green's functions. Table 1 lists the locations of the mainshock hypocenter, as determined by the Southern California Seismic Network (USGS/CIT) and as determined with Kanamori's code. Table 2 lists the locations of the TERRAscope stations. In southern California, realtime warning in urban Los Angeles of a large event on the San Andreas Fault would be helpful. In this article we use the Sierra Madre mainshock as a reciprocal example. It occurred near Los Angeles and was recorded near the San Andreas Fault and beyond it in the southern Sierra Nevada and the Mojave Desert.

The data from the TERRAscope stations are shown in Figure 2 . The records are shown with the correct timing 
relative to the event origin time. The time windows of the four inversions are indicated at the top. In the last inversion the windowing of the data at GSC, ISA, and PFO varies slightly because differences in source-receiver paths affect the $P$ and $S$ arrival times. The exact data window is shown for each station by the vertical lines. Each station is plotted at the maximum amplitude for the data at that station.

Figure 3 shows how the estimate of the source mechanism and magnitude of the Sierra Madre mainshock changes with time after the source rupture. The four mechanisms

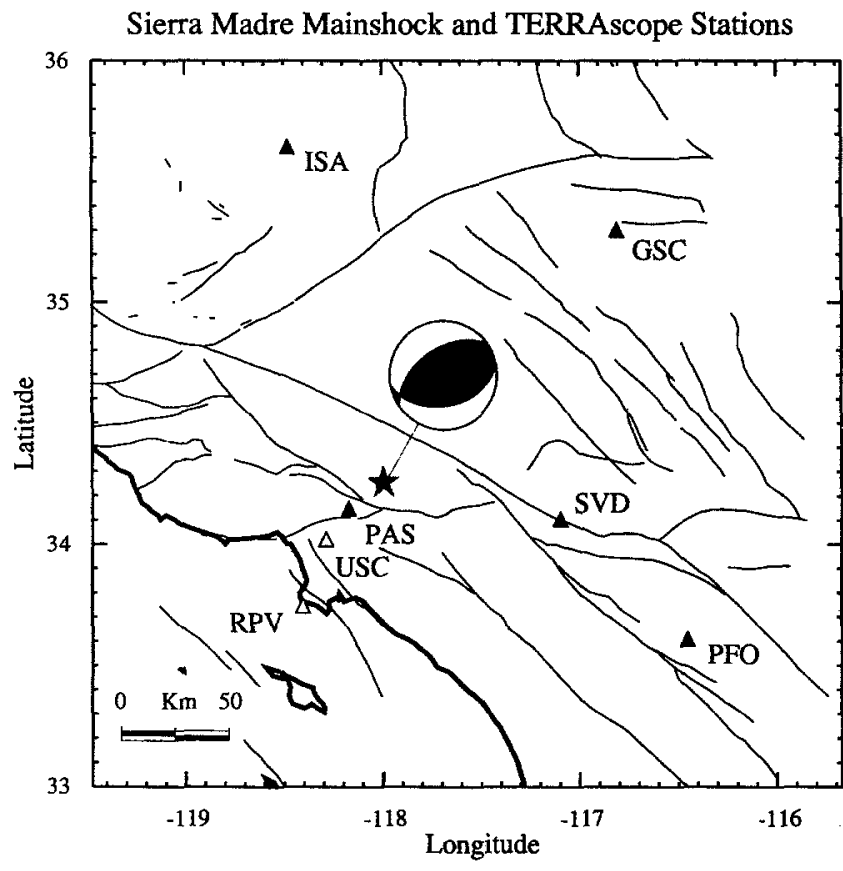

Figure 1. A map of southern California with the location of the 28 June 1991 Sierra Madre mainshock and the TERRAscope stations used in this study. The source mechanism shown was found by Dreger and Helmberger (1991) with the complete waveforms from these stations and refined Green's functions. The black triangles are stations used in the source inversion of the Sierra Madre event. The white triangles are stations are mentioned in the discussion of basin response in the Discussion section.

Table 2

Station Locations*

\begin{tabular}{llcccc}
\hline Station & \multicolumn{1}{c}{ Description } & $\begin{array}{c}\text { Latitude } \\
(\mathrm{N})\end{array}$ & $\begin{array}{c}\text { Longitude } \\
(\mathrm{W})\end{array}$ & $\begin{array}{c}\text { Distance } \\
(\mathrm{km})\end{array}$ & $\begin{array}{c}\text { Azimuth } \\
(\mathrm{)})\end{array}$ \\
\hline PAS & Pasadena & 34.148 & 118.172 & 18.7 & 233 \\
SVD & Seven Oaks Dam & 34.104 & 117.098 & 84.4 & 100 \\
GSC & Goldstone & 35.300 & 116.810 & 160.6 & 42 \\
ISA & Lake Isabella & 35.643 & 118.480 & 163.8 & 348 \\
PFO & Pinon Flats & 33.609 & 116.455 & 158.9 & 116 \\
USC & Univ. So. Cal. & 34.019 & 118.286 & & \\
RPV & Palos Verde & 33.744 & 118.403 & &
\end{tabular}

*Distance and azimuth from the single-station location of the Sierra Madre mainshock for stations used in inversions. correspond to inversions with the data available at that time after the event. The radius of the mechanism diagram is proportional to the seismic moment. The source mechanism found by Dreger and Helmberger (1991) is shown in the upper right corner of the figure. The inversions were done using Green's functions calculated from a standard southern California crustal model (Table 3). The source depth was set to $11 \mathrm{~km}$, since this is about half the thickness of the seismogenic zone in southern California. A triangular source time function lasting $1 \mathrm{sec}$ was convolved with the Green's functions. For the inversions discussed in this article, the duration of the source-time function was determined by inspection of the width of the PAS $P$ wave, but an estimate of the width of the source time function can be made automatically by finding the time between zero crossings of the $P$ wave. The first inversion solution, based only on the PAS $P$

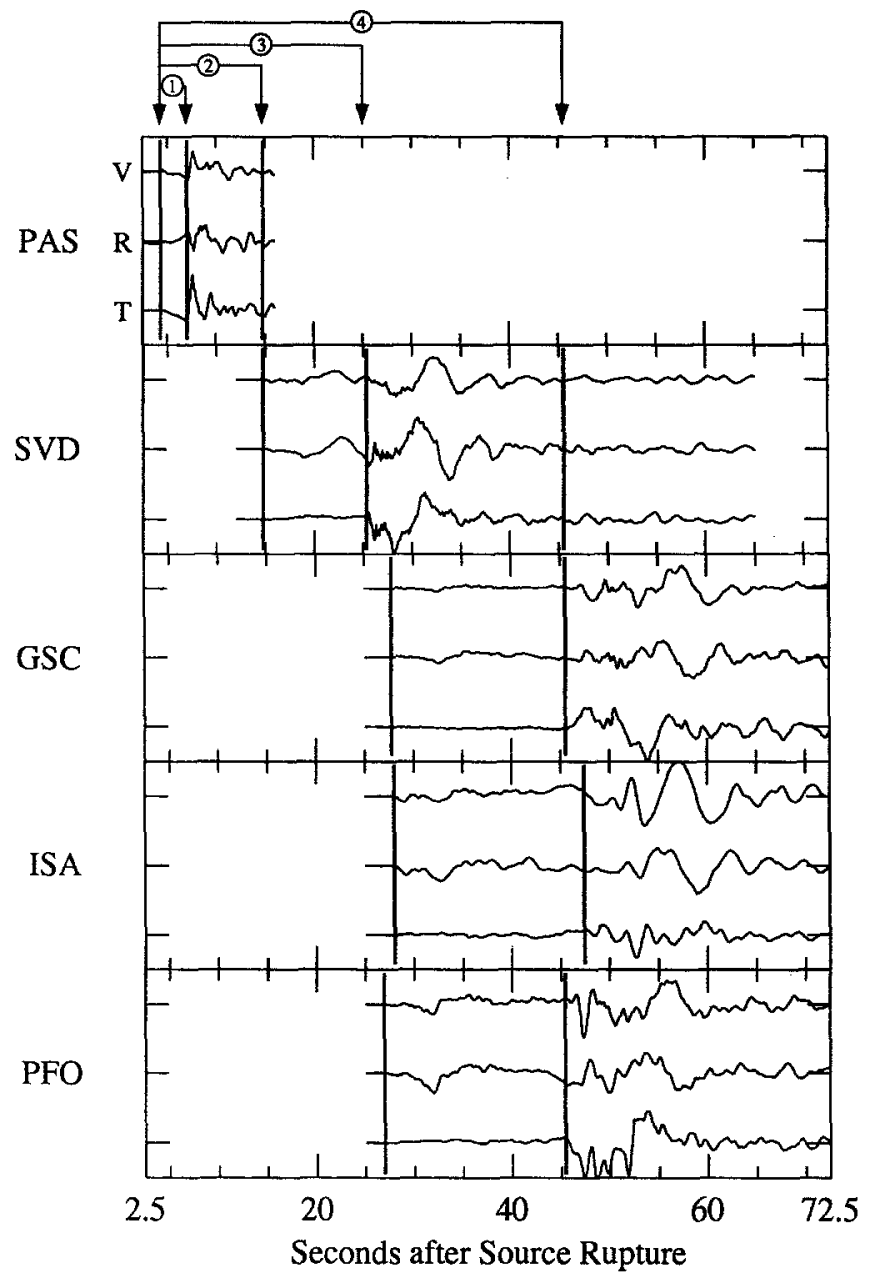

Figure 2. Data from TERRAscope stations for the 28 June 1991 Sierra Madre mainshock. The waveforms are plotted relative to the event origin time. The amplitude of each waveform is relative to the maximum value recorded at that station. The arrows at the top indicate roughly the time windows used for the four inversions. The vertical lines for each station indicate the windowing more precisely. 
wave, has a significant strike-slip component and a seismic moment that is $30 \%$ too small. The second inversion is based on the entire PAS record. The strike of this solution is rotated about $180^{\circ}$ relative to the first inversion, and the thrust component is slightly greater. The moment is $20 \%$ less than that determined by Dreger and Helmberger.

The remaining two mechanisms in Figure 3 indicate how the solution changes with the addition of data from stations SVD and GSC, ISA, and PFO. The strike and rake fluctuate slightly, but the mechanisms remain predominantly thrust. The moment increases by about 20 to $30 \%$ over the second mechanism.

Figures 4 through 7 display the evolution of the fit of the synthetic waveforms to data. In these figures the data waveforms for SVD, GSC, ISA, and PFO are offset behind those of PAS by the appropriate relative travel time. This indicates the time it took the wave fronts to propagate to these stations after the Sierra Madre mainshock rupture. The boxes in each figure enclose the data that were used for that inversion. The Green's functions used for station PAS in the first inversion are calculated for a range of $30 \mathrm{~km}$. The actual distance from the Sierra Madre epicenter to the Pasadena station is $20.6 \mathrm{~km}$. The use of the $30-\mathrm{km}$ Green's functions shows what can be done before the range is accurately known (see discussion above). For the remaining inversions we use a range of $20 \mathrm{~km}$, the epicentral distance found with the PAS data (Table 2).

Figure 4 shows data and synthetic waveforms for an

Change in Estimate of Source Mechanism with Increase in Available Data

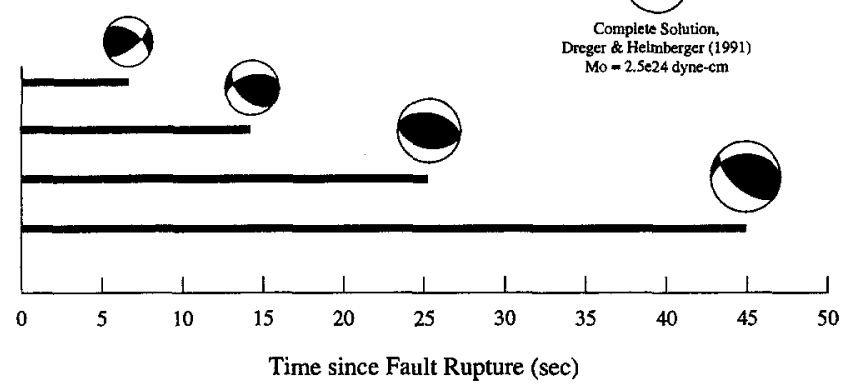

Figure 3. How the estimate of the source mechanism and magnitude of the Sierra Madre mainshock changes with time after the source rupture. The four mechanisms correspond to inversions with the data available at that time after the event. The size of the mechanism is proportional to the seismic moment, $M_{0}$. The source mechanism found with the complete TERRAscope records from PAS, SVD, GSC, ISA, and PFO (Dreger and Helmberger, 1991) is shown in the upper right corner of the figure. The inversions were done using Green's functions calculated from a standard southern California crustal model (Table 3). The Green's functions were calculated for a source of depth $11 \mathrm{~km}$ with a triangular source-time function lasting $1 \mathrm{sec}$. inversion using only the PAS $P$ waves and $30-\mathrm{km}$ Green's functions. The $P$-wave segment is so short that only the overall slope of the waveform controls the inversion. Also, the preferred shift of the inversion code between the vertical $P$-wave data and synthetic waveforms produces an overlap of only a few points. The code automatically rejects such weak fits. The result is that the first inversion is only dependent on the radial $P$ wave. This is not robust. The predicted waveforms for the unused portions of the data, calculated using this mechanism, are poor fits to the data. Any waveform fit between the data and synthetic waveforms at stations SVD, GSC, ISA, and PFO can only be considered happenstance.

Figure 5 shows the data and synthetic waveforms for an inversion using the entire PAS waveform. The result is definitely more strongly constrained. The source-inversion routine has produced good shear-wave fits for all three components of the inverted data from PAS. The predicted waveforms at the other stations generally compare well with data also. The $P n l$ waveform synthetics for the vertical and radial components of SVD, GSC, ISA, and PFO fit the data as well as they are likely to, given the generic southern California model on which they are based. The most significant misfits are found in the Love waves of SVD and ISA, and the Rayleigh waves of ISA. The inversion solution is nodal for Love waves at SVD and nonnodal for them at ISA, while the data are the opposite. The Rayleigh waves of the radial component of SVD are underestimated by a factor of 3 . The amplitude of the other Rayleigh-wave synthetics is within $25 \%$ of the amplitude of the data.

Figures 6 and 7 show the inversion results when the SVD Pnl data and the whole SVD record and GSC, ISA, and PFO $P n l$ waveforms are included, respectively. The additional data do not improve the overall fit of the synthetics to the data much. Improvements of the Rayleigh wave for ISA are offset by changes in the synthetics for PFO. The inversion fit of the vertical Pnl data at PFO (Fig. 7) is odd, but it is not detrimental to the overall waveform shape. Even when the SVD data are included in the inversion, the fit between the data and synthetic waveforms at this station does not improve. This is an indication that the southern California Green's functions are not as appropriate for this station as for the others. They are clearly good enough, though, that the SVD data do not make the inversion results worse. Station SVD was not placed at its location because of optimal site conditions. It was placed there to monitor ground mo-

Table 3

Southern California Crustal Model

\begin{tabular}{cccc}
\hline $\begin{array}{c}V_{p} \\
(\mathrm{~km} / \mathrm{sec})\end{array}$ & $\begin{array}{c}V_{s} \\
(\mathrm{~km} / \mathrm{sec})\end{array}$ & $\begin{array}{c}p \\
\left(\mathrm{~g} / \mathrm{cm}^{3}\right)\end{array}$ & $\begin{array}{c}\text { Depth } \\
(\mathrm{km})\end{array}$ \\
\hline 5.5 & 3.18 & 2.40 & 0.0 \\
6.3 & 3.64 & 2.67 & 5.5 \\
6.7 & 3.87 & 2.80 & 16.0 \\
7.8 & 4.50 & 3.00 & 35.0 \\
\hline
\end{tabular}


tions at the Seven Oaks Dam site. Since 1991, the size of the broadband network in southern California has grown dramatically. Station density has improved to the point that more desirable sites can be chosen for early-warning-rapidresponse monitoring.

\section{Discussion}

The Sierra Madre earthquake is the focus of this article because its location provides the right geometry to compare solutions based on near-source data and data recorded at San Andreas-to-Los Angeles distance. It is also large enough to be recorded at regional distances, so there is a well-determined complete solution as a reference. It is not an unusually good event for a single-station source determination. The inversion for data from just one local station would be better if the Green's functions were refined for that particular area. This can be done with small events or a previous moderate event in the area. For the path from the Sierra Madre mainshock to PAS, for example, Dreger and Helmberger (1991) use Green's functions calculated for a model based on the 1988
Upland earthquake sequence to the east (Dreger and Helmberger, 1990).

Another refinement would be incorporating the effects of local receiver structure in ground-motion predictions. The effect on waveforms of lateral heterogeneities in the crust can be significant. As an example, the change in the response due to the Los Angeles basin is dramatic when records are compared from the PAS and USC TERRAscope stations. Weak motions can be used to develop transfer functions needed to map hard rock response, such as at PAS or RPV, into the basin response, such as at USC. Incorporating local receiver structure would be based on a catalog of either empirical Green's functions or theoretical Green's functions calculated from a velocity model of the receiver structure. Empirical Green's functions would be recordings of small events on the perimeter of the receiver structure. Creating a catalog of empirical Green's functions is most feasible in areas with a dense network of broadband stations. Theoretical Green's functions are more flexible than empirical Green's functions because they can incorporate arbitrary source parameters. If the receiver structure is complex, however, it may be very difficult to model it adequately. Figure

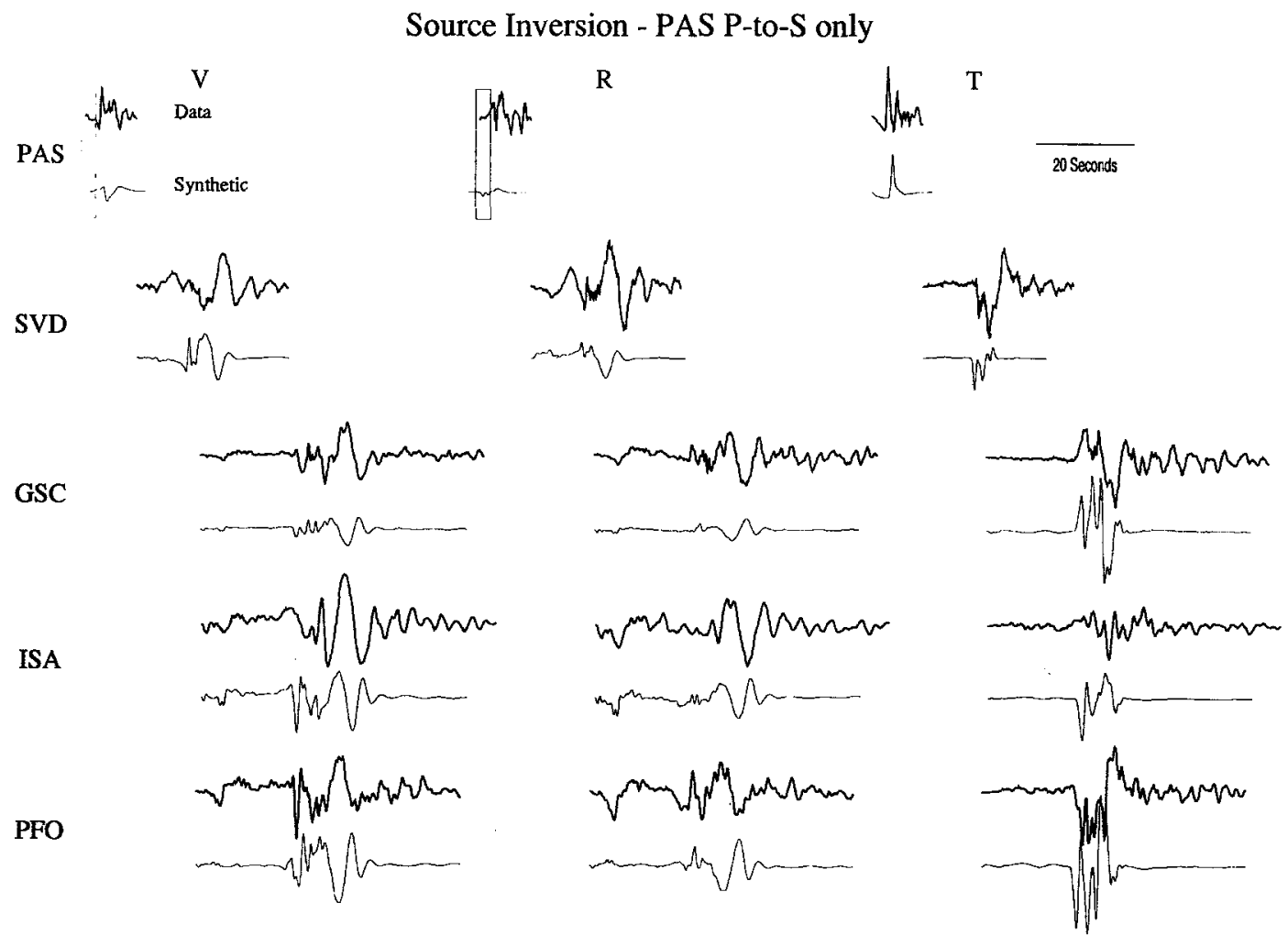

Figure 4. Data and synthetic waveforms for the inversion using only the PAS Pnl waveforms. The source mechanism found is strike $(\Phi)=305^{\circ}$, dip $(\delta)=55^{\circ}$, rake $(\lambda)=150^{\circ}$, and seismic moment $\left(M_{0}\right)=1.9 \times 10^{24}$. The data waveforms for SVD, GSC, ISA, and PFO are offset behind those of PAS by the appropriate relative travel time. This indicates when energy arrived at these stations after the Sierra Madre mainshock rupture. The boxes around the $P$-wave portion of the PAS vertical and radial components outline the data used for this inversion. The box on the vertical component is dashed to indicate that the inversion code rejected the fit within this window automatically (see text). 
Source Inversion - Whole PAS Record

PAS

GSC

ISA
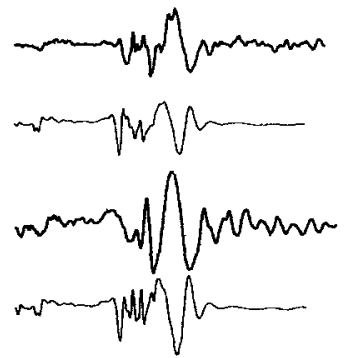

PFO

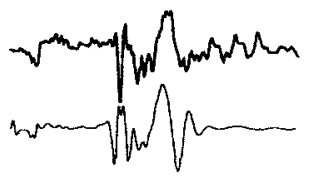

$\mathbf{R}$
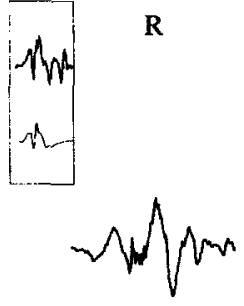

man

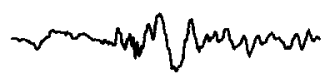

mponmonar

mund Murmor

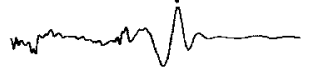

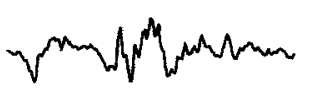

momenn
$T$
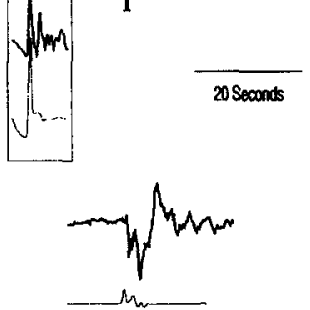

Figure 5. Data and synthetic waveforms for the inversion using the entire PAS waveform. The source mechanism found is $\Phi=130^{\circ}, \delta=50^{\circ}, \lambda=130^{\circ}$, and $M_{0}=$ $2.1 \times 10^{24}$.

Source Inversion - Whole PAS + SVD Pnl

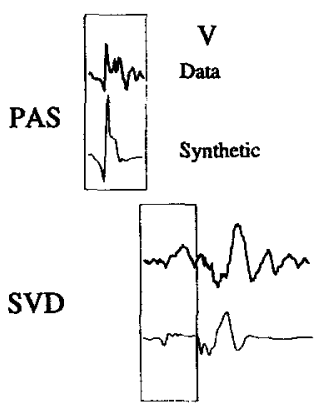

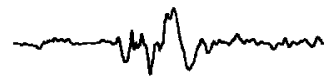

GSC

ISA

PFO

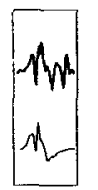

$\mathbf{R}$

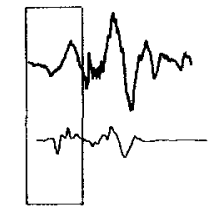

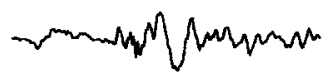

mannown

$\operatorname{man} N \sqrt[M m u r]{ }$

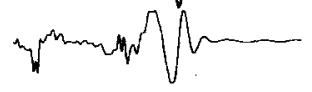

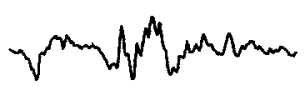

rimanon
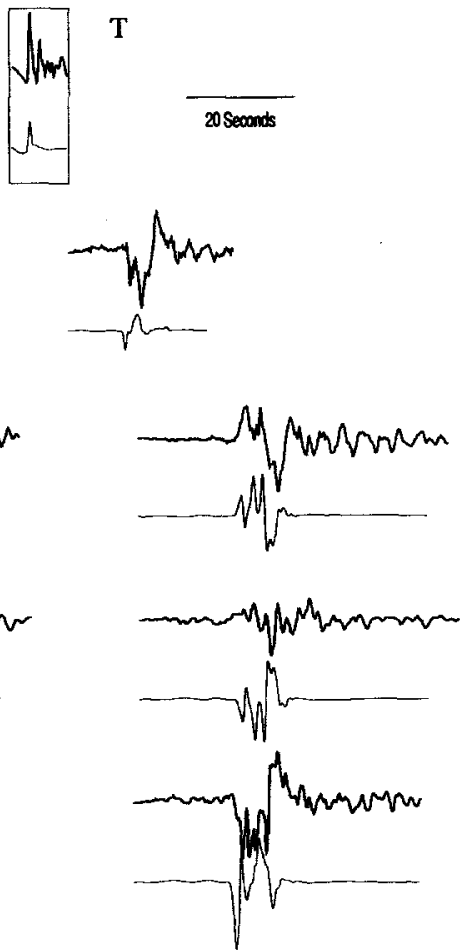

Figure 6. Data and synthetic waveforms for the inversion using the entire PAS record and the $P$ Pl portion of the SVD waveforms. The source mechanism found is $\Phi=100^{\circ}$, $\delta=45^{\circ}, \lambda=90^{\circ}$, and $M_{0}=2.5 \times 10^{24}$. 


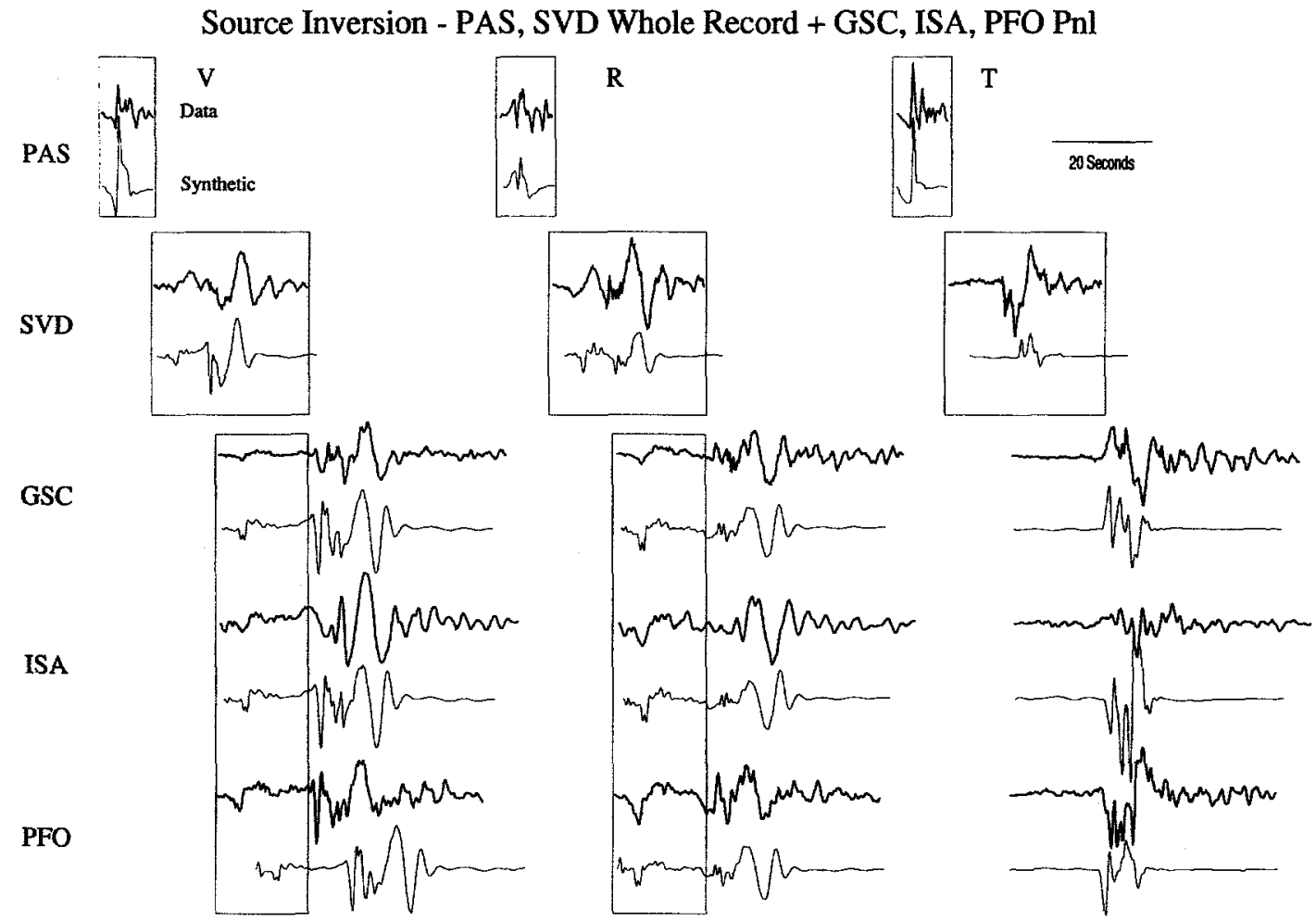

Figure 7. Data and synthetic waveforms for the inversion using the entire PAS and SVD records and the Pnl portion of the GSC, ISA, and PFO data. The source mechanism found is $\Phi=130^{\circ}, \delta=60^{\circ}, \lambda=115^{\circ}$, and $M_{0}=2.7 \times 10^{24}$.
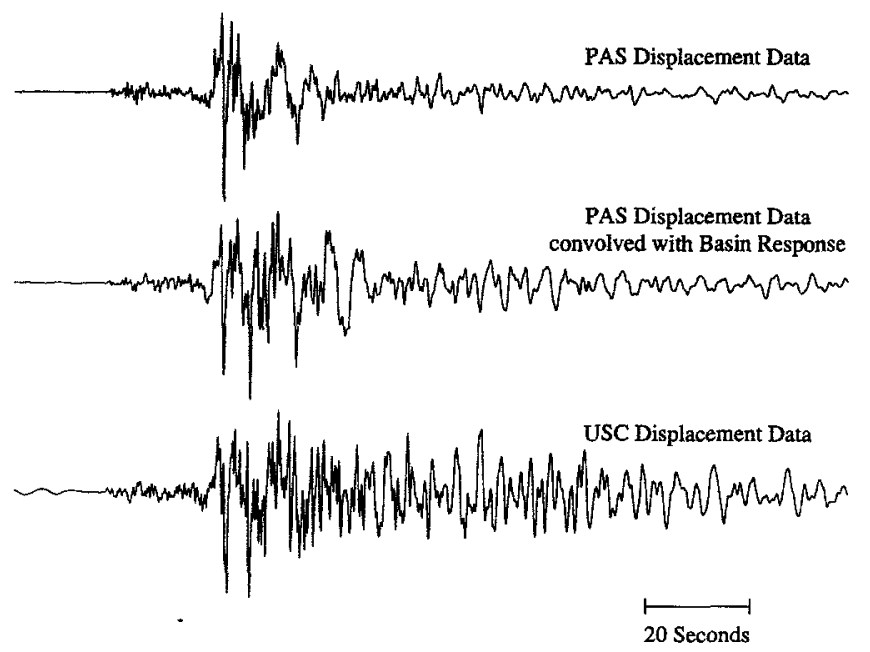

Figure 8. Comparison of a USC displacement record with a convolution of the PAS record with a theoretical response for the Los Angeles basin. The USC and PAS records are from a 21 August 1993 event $(M=4.2)$ on the San Andreas Fault near Palm Springs. The basin response is from Scrivner and Helmberger (1994).
8 shows the convolution of a theoretical two-dimensional basin response with a record from station PAS. It is compared with the record at the USC station in the city of Los Angeles. The basin response was generated by modeling the $M=5.3$ aftershock of the 1987 Whittier Narrows sequence just east of Los Angeles (Scrivner and Helmberger, 1994). The earthquake that this response is convolved with is a $M=4.2$ event that occurred on 21 August 1993 on the San Andreas Fault near Palm Springs. The convolved waveform compares well with the USC data for about $15 \mathrm{sec}$ after the $S$ wave, but it does not match the long duration of the USC data.

Dreger and Helmberger (1991) filtered the data from stations SVD, GSC, ISA, and PFO with the response of a Press-Ewing 30-90 instrument to remove the effect on the inversion of high-frequency waves. An inversion based on long-period data is more stable than an inversion with broadband data. Green's functions from simple one-dimensional models do not contain the high-frequency waves to match broadband data. Small shifts between the data and synthetic waveforms can have a big effect on the waveform fit param- 
eter. The width of the source time function is a less important factor in a long-period inversion because the corner frequency of the source is higher than the frequency band of the data and the source time function is smoothed out. An additional advantage of working with filtered data is that long-period data can be sampled more sparsely, and, after the initial delay to do the filtering and decimation, the inversion is computationally quicker. Zhao and Helmberger (1994) have compared long-period and broadband inversions of the Sierra Madre mainshock and other events.

However, there are advantages to working with broadband data. Much of the information in data from stations near the earthquake is in higher frequencies than are retained by long-period instruments. Utilizing this information, though, does depend on having adequate Green's functions. Broadband data are available for small events with high corner frequencies that would be swamped by noise on longperiod records. These smaller events are potentially useful as test and calibration events for the system. Broadband data also contain the frequency content to attack more subtle questions about an event, such as directivity and determination of the fault plane. Song and Helmberger (1995) have developed a technique to make rapid determinations of source dimensions and directivity.

In the results shown here the depth and source-time functions are fixed for all inversions. The inversion does not solve for these parameters, but repeated inversions can be done for different depths and source time functions to find the best fit. With improved Green's functions around the closest station, the depth estimate of the event can be improved. In order to do repeated inversions, the inversion code must run quickly. The inversions discussed in this article were run on a Sun SPARCstation 2 and a SPARCstation 10. On a SPARCstation 2, the inversion of the whole PAS waveform took $23 \mathrm{sec}$. On a SPARCstation 10 , this inversion took only $12 \mathrm{sec}$. These times are only for the inversion itself and do not account for data transfer and preprocessing.

A number of real-time broadband systems are presently being installed in urban regions around the world. These stations are capable of recording both strong and weak motions. Since weak motions are common, a catalog of Green's functions (empirical and theoretical) can be built for the region. This would include developing transfer functions needed to map hard rock response to nearby soft soil or basin sites. Using the Los Angeles area as an example, the strategy discussed in this article suggests that it is possible to predict the ground motions in the Los Angeles basin for an earthquake on the San Andreas Fault more rapidly than the seismic energy can propagate to the basin. This article is intended to be the first step in testing the credibility of this strategy.

Unfortunately, the whole system can fail for many reasons. Large events require distributed source models that are more complicated than point source models adequate for small events. For large events it becomes more difficult to separate propagation effects from source effects. Also, the event could occur in a basin. In this case it would be difficult to invert the waveform from the nearest station for source parameters. The USC record of the 17 January 1994 Northridge earthquake is an example of this (Song et al., 1995). A nearby station may also stop working, as happened to station RPV prior to the Northridge event. We think these problems can be overcome as broadband systems mature and more broadband data are modeled.

\section{Acknowledgments}

We thank Hiroo Kanamori for his comments on this article. This research was supported by the Southern California Earthquake Center, U.S. Geological Survey Grant Number 1434-93-G-2322, and CURIE-Kajima. This is Contribution No. 5403, Division of Geological and Planetary Sciences, California Institute of Technology, Pasadena, California.

\section{References}

Bache, T. C., S. R. Bratt, J. Wang, R. M. Fung, C. Kobryn, and J. W. Given (1990). The intelligent monitoring-system, Bull. Seism. Soc. Am. 80, 1833-1851.

Crampin, S. and C. J. Fyfe (1974). Automatic analysis of tape-recordings from seismic networks, Geophys. J. R. Astr. Soc. 39, 155-168.

Dreger, D. and D. V. Helmberger (1990). Broadband modeling of local earthquakes, Bull. Seism. Soc. Am. 80, 1162-1179.

Dreger, D. and D. V. Helmberger (1991). Source parameters of the Sierra Madre earthquake from regional and local body waves, Geophys. Res. Lett. 18, 2015-2018.

Dreger, D. and D. V. Helmberger (1993). Determination of source parameters at regional distances with three-component sparse network data, J. Geophys. Res. 98, 8107-8125.

Ekström, G., A. M. Dziewonski, and J. M. Stein (1986). Single station CMT: application to the Michoacan, Mexico, earthquake of September 19, 1985, Geophys. Res. Lett. 13, 173-176.

Horiuchi, S., T. Matsuzawa, and A. Hasegawa (1992). A real-time processing system of seismic-wave using personal computers, J. Phys. Earth 40, 395-406.

Magotra, N., N. Ahmed, and E. Chael (1987). Seismic event detection and source location using single-station (three-component) data, Bull. Seism. Soc. Am. 77, 958-971.

Michael, A. J., S. P. Gildea, and J. J. Pulli (1982). A real-time digital seismic event detection and recording system for network applications, Bull. Seism. Soc. Am. 72, 2339-2348.

Nakamura, Y. (1988). On the urgent earthquake detection and alarm system (UrEDAS), in Proc. of the 9th World Conference on Earthquake Engineering, 2-9 August 1988, Tokyo-Kyoto, Japan, Vol. VII.

National Research Council (1991). Real-time earthquake monitoring: early warning and rapid response, Committee on Seismology, National Academy Press, Washington, D.C., 52 pp.

Reymond, D., O. Hyvernaud, and J. Talandier (1991). Automatic detection, location and quantification of earthquakes: application to tsunami warning, Pure Appl. Geophys. 135, 361-382.

Roberts, R. G., A. Lindfors, A. Christoffersson, R. Bodvarsson, and S. T. Rognvaldsson (1993). 3-component data as an aid to seismic event detection and association: a case-study using data from the SLL (Iceland) network, Comput. Geosci. 19, 123-134.

Scrivner, C. W. and D. V. Helmberger (1994). Seismic waveform modeling in the Los Angeles basin, Bull. Seism. Soc. Am. 84, 1310-1326.

Song, X., L. Jones, and D. V. Helmberger (1995). Source characteristics of the January 17, 1994 Northridge earthquake from regional broadband modeling, Bull. Seism. Soc. Am. (submitted for publication).

Song, X. and D. V. Helmberger (1995). Source estimation of finite faults from broadband regional networks, Bull. Seism. Soc. Am. (submitted for publication). 
Stewart, S. W. (1977). Real-time detection and locations of local seismic events in central California, Bull. Seism. Soc. Am. 67, 433-452.

Uski, M. (1990). Event detection and location performance of the FINESA array in Finland, Bull. Seism. Soc. Am. 80, 1818-1832.

Zhao, L. and D. V. Helmberger (1994). Source estimation from broadband regional seismograms, Bull. Seism. Soc. Am. 84, 91-104.
Seismological Laboratory 252-21

California Institute of Technology

Pasadena, California 91125

Manuscript received 15 April 1994 